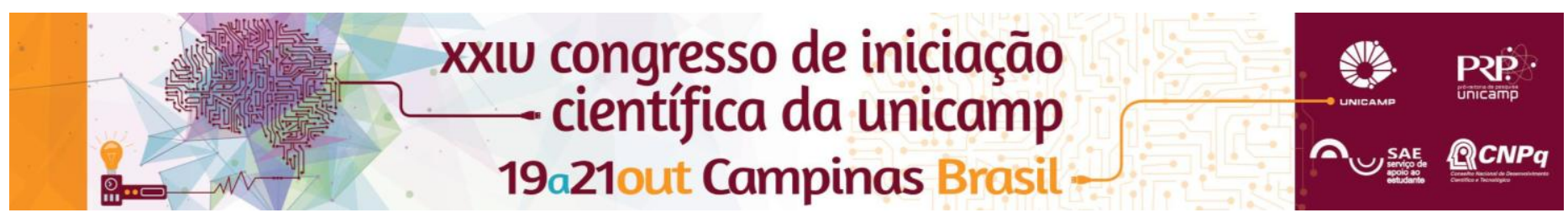

\title{
Expression, purification and characterization of AHA1 sorghum protein, a co-chaperone from Hsp90 system.
}

\section{Débora Bueno Toledo*, Conrado de Campos Gonçalves, Prof. Dr. Carlos Henrique Inácio Ramos}

\begin{abstract}
Proteins are responsible for a wide range of cellular processes. In order to perform these functions, they must reach a specific three-dimensional conformation that depends on the correct folding process. The molecular chaperone and cochaperones are very important in cellular proteostasis, since they help other proteins to achieve the native conformation. One of the most important chaperone families for these processes is Hsp90 (Heat-shock protein $90 \mathrm{kDa}$ ). The cochaperone AHA1, together with many other co-chaperones, assists Hsp90 in their ATPase activity. This work focuses on the biophysical characterization of protein AHA1, using techniques such as circular dichroism, intrinsic fluorescence of tryptophan and SEC-MALS; other experiments will be performed in the future. By studying these characteristics of AHA1, we aim to better understand its structure, how the complex with Hsp90 is formed, and elucidate possible functional mechanisms related to Hsp90. The AHA1 protein studied in this work comes from Sorghum bicolor, an important organism for agriculture, being the fifth most produced cereal in the world.
\end{abstract}

\section{Key words:}

Biochemistry, proteins, co-chaperones

\section{Introduction}

Hsp90 is a conserved molecular chaperone, responsible for the folding and activation of several client proteins involved in various cellular processes. The large number and the diversity of these client proteins demand a high adaptiveness of Hsp90 towards the need of the individual client. This adaptiveness is amongst others mediated by more than 20 so-called cochaperones that differ in their actions towards Hsp90. Some of these cochaperones are able to modulate the ATPase activity of Hsp90, like Aha1, and/or its client protein binding, folding and activation. This work aims at the production, purification and characterization of AHA1 from Sorghum bicolor (SbAHA1), co-chaperone of the Hsp90 system.

\section{Results and Discussion}

Image1.Heterologous expression and solubility test of $\mathrm{SbAHA} 1$ induced at $37^{\circ} \mathrm{C}$ for $4 \mathrm{~h}$. SDS-PAGE of the bacterial samples colleted hours after addition of the inducer IPTG. The samples were then lysated and centrifuged. $\mathrm{M}$ : molecular marker; $\mathrm{T}$ : total protein; $\mathrm{S}$ : soluble proteins; $\mathrm{P}$ : proteins in the precipitate.

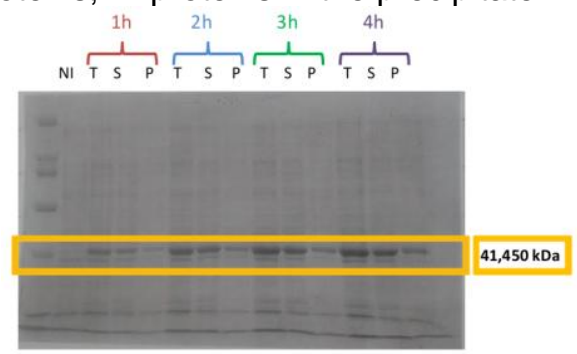

Image2: Chromatograms and SDS_PAGE related to linear affinity and gel filtration
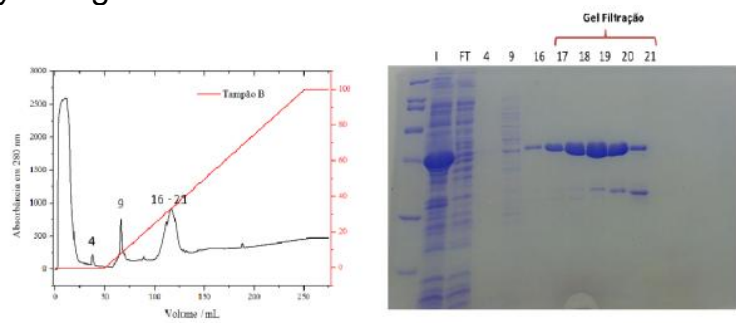
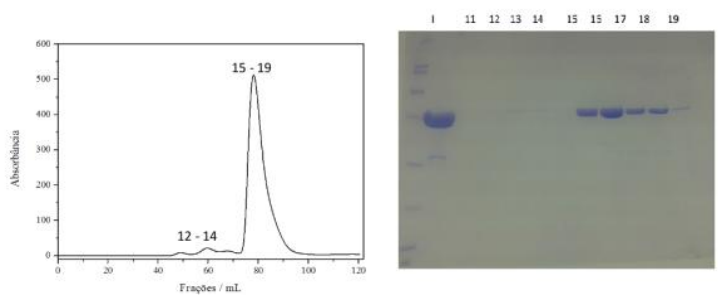

Image 3: CD spectrum obtained for the global composition of secondary structure of SbAha1, thermal unfolding from $20{ }^{\circ} \mathrm{C}$ to $90^{\circ} \mathrm{C}$ and fluorescence spectrum comparing the protein with and without the presence of guanidine:

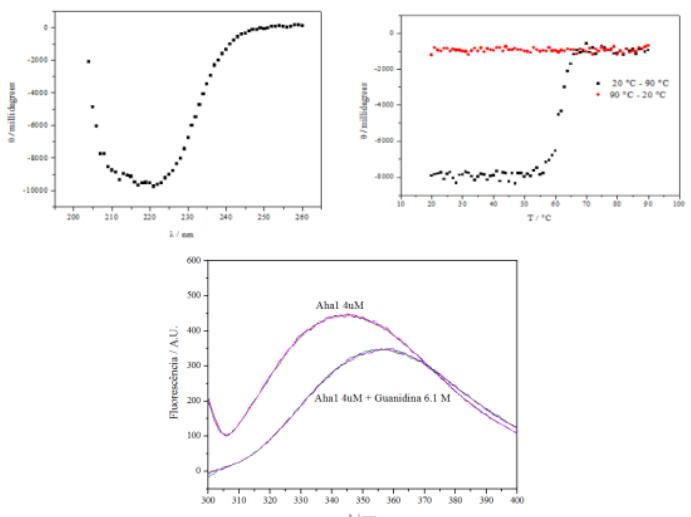

\section{Conclusions}

The protein was expressed soluble and obtained folded and pure by two chromatographic steps with over $95 \%$ purity. There was a predominance of the $\alpha$-helix secondary structure $(\sim 33 \%)$ and thermal unfolding showed a Tm of 55 ${ }^{\circ} \mathrm{C}$. The fluorescence showed that the protein is at least partially coiled, since at least one tryptophan was exposed in an environment with guanidine.

\section{Acknowledgement}

UNICAMP, Institute of Chemistry and SAE

\footnotetext{
${ }^{1}$ Borges JC, Ramos CH. Protein folding assisted by chaperones. Protein Pept Lett. 2005 12: 257- 61.2 Voet, D. ; Voet, J.G.; Pratt, C.W. ; Fundamentos de Bioquímica, $4^{\mathrm{a}}$ edição, 2014, Editora Artmed.
} 